\title{
Editorial
}

\section{Pediatric cardiology en route to the third millennium-un long fleuve tranquille?}

\author{
Jean Kachaner \\ Service de Cardiologie Pédiatrique, Hopital Necker-Enfants Malades, Paris
}

\begin{abstract}
Pour dire l'émotion en étant sûr d'être authentique, comment ne pas recourir à la langue des sentiments, c'est-à-dire ma langue maternelle. Je voudrais donc que vous sachiez combien je suis fier, moi ce fils d'émigrant fuyant la misère et les pogroms et qui n'avait de richesse que celle, immense, du coeur, d'être ici, devant vous, choisi par vous quiêtes mes maitres, mes pairs, mes amis, pour rendre hommage au pionnier qu'était Edgar Mannheimer et rejoindre ainsi dansl'honneur une poignée de prédécesseurs illustres. J'aime cet instant qui est ma joie et souhaite, en vous disant merci de me l'avoir offert en privilège, le dédier à toute l'équipe qui partage avec passion ma vie de médecin.
\end{abstract}

$\mathrm{P}$

EDIATRIC CARDIOLOGY WAS BORN ABOUT FORTY YEARS ago, at a time when open heart surgery became able to offer more than contemplation, compassion, and flowers as therapy. It evolved in the fashion of a long quiet river, with two sudden accelerations in the seventies. These can be considered as cultural revolutions, since they served to change drastically the landscape-ultrasonic imaging techniques ${ }^{1}$ and neonatal pharmacology, the latter dominated by the prostaglandins. ${ }^{2}$ As part of the evolution, pediatric cardiology became more accurate, more efficient, and safer than it had ever been. It became neonatal cardiology and already has become fetal cardiology. Further advances in noninvasive methods of diagnosis, new surgical concepts and techniques, tremendous improvements in pre- and postoperative monitoring and care, together with a surprising rise of percutaneous techniques of treatment, have elevated our specialty up to enviable levels of excellence.

But looking at our progress during the last decade, and particularly at the major two or three loops recently followed by our river, can we depend upon its future

Presented as the Edgar Mannheimer Lecture at the 29th Annual Meetıng of the Association of European Paediatric Cardiologists, Edınburgh, May, 1994

Accepted for publication 23 June 1994 tranquillity? We are certainly attacking more and more complex conditions, including those considered hopeless not very long ago. But in which ways? The weapons used include palliative procedures, with indications which have increased vertically despite some shadows on their fate; transplantations have become accepted for patients at any age, and at any rate, although the longterm consistency of this treatment is far from established; terminations are accepted when there are no cultural obstacles to make a difference between a fetus at 24 weeks of gestation and a two-day-old neonate. Is the next weapon to be selection, when molecular genetics and biology have progressed a little more?

I do not want to emphasize these points so as to deliver a pessimistic view on our discipline. But, at the turn of this century, which is also the turn of the millennium, we must be aware that pediatric cardiology is still suffering from a crisis of growth. It is not going to provide us with the serenity of a "long fleuve tranquille." Turbulent waters are rather to be expected. We must face these rapids openly for a better control of the treacherous stretches. What are these matters of concern? Complexity, perverse effects, and trends towards destabilization.

\section{Complexity}

As long as practitioners in pediatric cardiology had only binary choices, to do or not to do, essentially meaning to operate or not, things were rather simple. Conceptual and technical advances have brought many additional options. This has resulted in a far more complex field of medicine which requires wider knowledge and expertise, as well as more equipment and greater expense. Is every pediatric cardiologist, or even every academic group embracing pediatric cardiology, prepared to encourage this evolution? They certainly should. Let us consider examples drawn from our daily practice. 


\section{Patency of the arterial duct}

Which lesion is simpler than a patent duct? Weren't we taught, not very long ago, to identify such a lesion simply by listening at a continuous murmur heard beneath the clavicle with a plain stethoscope, to confirm it by catheterization, and to fix it as soon as diagnosed by the simplest operation ever designed for a congenital cardiovascular malformation?

We may still adopt such an attitude. But color Doppler echocardiography has replaced invasive studies. ${ }^{3}$ This is certainly good, but the technique has led to diagnoses of infraclinical small ducts which would certainly have been overlooked in the past without the patient suffering any damage. Moreover, we can now close the ducts with devices delivered through catheters, thus avoiding surgery. ${ }^{4}$ Is this an advantage? Not always, since closure with umbrellas seems not as efficient as was surgical division or ligation. It is not free from complications, such as embolizations, hemolysis, obstruction of pulmonary arterial branches, and even death. It may be limited by the age of the patient, the size of the duct, and, in many countries, by an unfavorable ratio of cost to benefit. Interestingly enough, the topic of a recent debate included in the Cardiology in the Young Conference held in London some weeks ago was: the less your parient needs occlusion of the duct, the better is the indication! The debate is not over. We now have a further option, which is back to the future, and introduces videosurgery. François Laborde has shown nicely how simple it is to introduce a couple of tubes into the mediastinum via thoracoscopy in order to dissect the duct and to clip it just by looking at the television screen. ${ }^{5}$ Is it as safe as conventional surgery? Yes, he says. But I know of one patient who died from irretrievable hemorrhage in other hands. Good hands, but hands on this learning curve.

\section{Obstructive lesions}

Another simple condition is aortic coarctation. It can be recognized simply from absence of the femoral pulses and a gradient in blood pressure between the upper and lower limbs. It can be imaged on the levophase of a right heart angiogram and, again, fixed surgically between the ages of 0.5 and two years, depending on the experience of the surgeon. Such an approach used to provide splendid results in all well trained centers, with no mortality and low morbidity.

It's not that simple nowadays. We now have ultrasound and magnetic resonance to provide our images a simpler way. Better images? Not always, since the aortic arch is a rather complicated structure moving from one plane to another, making it difficult to cut and project it onto a single plane. A simpler way? Certainly for echo, but not for resonance imaging, since this technique requires a level of cooperation which often means either deep sedation or even general anesthesia.

Secondly, balloons have interfered with therapy. We may now enlarge an obstruction and reduce a pressure gradient with a balloon catheter. ${ }^{6}$ Do we always know at which rate? There is no magic in vascular dilation. We know that the so-called good result depends upon tearing the wall of the aorta. ${ }^{7}$ This may result in an aneurysm which can rupture months, or even years, after the maneuver.

Transcatheter valvotomies have now tended to replace surgery for the relief of valvar stenoses. As far as the pulmonary valve is concerned, there is no doubt that this represents a real advance and benefit for the patient. This is so even in the more severe cases, including critical stenoses in the neonate, provided a sophisticated and fully equipped laboratory is available, and one trained to deal with severely distressed neonates. But should we also blindly dilate aortic valves, with the incremental risk of significant aortic regurgitation? ${ }^{8}$ And of femoral artery occlusion?? The decision is far from obvious.

\section{Tetralogy of Fallot}

Assessment and management of a patient with tetralogy of Fallot had been well codified for decades, with the following steps. First was clinical suspicion, based on specific data, invasive confirmation and delineation of the disease. Then came simple follow-up of asymptomatic patients until they had reached the lowest age for complete repair at acceptable risk, the latter ranging from 0.3 to three years according to the centers. In symptomatic children not fulfilling requirements of age or size for curative surgery, an aortopulmonary shunt was created as a bridge to definitive therapy.

Modernity, competition, and fashion have modified this attitude. Tetralogy of Fallot is a widespread condition. The way it is managed has become an emblem. ${ }^{10}$ The more patients that can be sent to surgery on echocardiographic grounds alone, the smarter seems the physician, even if some atypical but dangerous coronary arterial arrangements are overlooked from time to time. Shunts have come to look like antiques. Every surgeon everywhere wants to show his or her ability to repair electively any kind of tetralogy early in infancy regardless of symptoms and of increased risks. Those who accept the idea of a palliation as the first stage now push for transcatheter balloon dilation of the outflow tract. This might be effective, but appears complex to achieve and is not devoid of new dangers, mostly in the very young. " Anyway, codification is over for these patients, but always to their final benefit? Certainly not always and not everywhere. Some have certainly become victims of progress. 


\section{Complete transposition}

Another, and more significant example, is given by complete transposition (concordant atrioventricular and discordant ventriculoarterial connections). Up to the mid-eighties there was a simple consensus. Detect the lesion as soon as possible, even in the fetus, and refer the patient to a specialized center for a staged protocol including balloon atrial septostomy as an emergency measure, followed by atrial correction (the Mustard or Senning procedure) some months later.

Since several brilliant surgeons introduced the arterial switch procedure in neonates, ${ }^{12-14}$ this convention exploded. In spite of a significantly higher surgical risk in the initial stages, the management of complete transposition became a matter of discussion from one center to another. A new challenging flag was hoisted. Furthermore, many additional questions were raised, such as: now we can achieve the switch in neonates, should we still balloon the atrial septum? If yes, should we do it in the catheter laboratory under X-rays, or at the bedside under echo control? Is there a need for imaging of the coronary arteries with conventional angiography, or can we detect the arrangement by ultrasound? Or can we just ignore it, and let the surgeon check in the operating room? Should we give prostaglandins prior to surgery in order to enhance mixing and promote the systemic competence of the left ventricle? If yes, should we give them prior to or only after atrial septostomy? ${ }^{15}$

The arterial switch procedure certainly avoids the well known late complications of the conventional atrial operations, such as arrhythmias and right ventricular dysfunction. It also makes more sense in being truly curative. But, without reemphasizing the high surgeon-dependant immediate risk, can we be sure that these patients are sheltered from another set of serious complications, such as myocardial dysfunction as a result of damage to the coronary arteries? We are currently collecting data in this field, and our preliminary results give cause for concern.

\section{Hearts with one big and one small ventricle}

My last example is certainly not the least. It addresses those complex malformations in which there is definitely no hope for biventricular repair. The group includes the various kinds of tricuspid or mitral atresia, double inlet left and right ventricle, as well as hypoplastic left or right heart syndromes. To discuss such cases some years ago gave the options of either simple palliation or abstention. Nowadays this would be considered a confession of powerlessness, and is no longer acceptable.

Firstly, because there is an irresistible promotion of the so-called cavo- or atriopulmonary bypass operations, ${ }^{16}$ a large number of techniques have been de- signed, all of these deriving from an old idea: the Glenn procedure brilliantly renewed by Francis Fontan a quarter of a century ago. ${ }^{17}$ Immediate results are certainly excellent in a majority of patients, particularly in those selected according to strict hemodynamic criteria. But the procedure is now often considered to be a complete repair and, therefore, becomes a fundamental aim to be achieved in any complex disease, overshadowing any other option. In reality, the long-term prognosis of these interventions is not yet established. Worse, that which is known is not very encouraging as far as ventricular function, atrioventricular valvar competence, pulmonary vascular integrity and electrophysiology are concerned..$^{18}$ We may become terribly disappointed at the turn of the millennium by the fate of many of these children.

Secondly, transplantation of either the heart or the heart and lungs is now considered a reasonable option for children, even very young, even those not already born. Some may elect for transplantation as a first line of therapy despite the fact that the scientific consistency is far from proven. ${ }^{19}$

Again, I am not trying to hide the sunny side of these new protocols. They certainly represent major advances. But remember that they bring with them new questions, making pediatric cardiology a very complex business, and removing it far from the "long fleuve tranquille."

\section{Perverse effects}

Other effects of progress and modernity are more discrete but may be considered as very perverse. Let us unmask briefly one or two of these.

Electronics and digits have entered our field, as in any other scientific area. They certainly produce great help in assessing morphology and physiology, as well as improving safety for the patient. But they may also invade our minds, obscuring what was called the common clinical sense, thus jeopardizing our ability to make the right diagnosis.

Not a year goes by without a child being referred to my clinic for advice on either an additional drug to treat an "idioparhic" cardiomyopathy, or on the opportunity to put him or her on the waiting list for transplantation. On investigation, we find that a coarctation of the aorta, an anomalous left coronary artery or a chronic ectopic tachycardia had been overlooked. Just because a highly sophisticated echo/Doppler study, performed as always in the dark, had replaced the complete clinical examination or a careful attention to the electrocardiogram. So, we must remember that our new instruments, sophisticated though they are, are just new tools in the box. Their availability should not make us forget the funda- 
mentals of medicine.

Fashion and elegance are other potential dangers, since they may interfere with the strategy of management regardless of the qualifications of the medical or surgical team in charge of the patients. This is another threat on our ability to dispense the best care to our children. I have already mentioned the emblematic value of several procedures, such as repair of tetralogy of Fallot in infancy, closure of an arterial duct with an umbrella, and, overall, switching the great arteries in the neonate with complete transposition. Pediatric cardiac surgeons are already classified into "switching" and "non-switching" operators. Pediatric cardiologists will soon, if not already, be split into "implanters" and "non-implanters," with the obvious pejorative connotation for the latter.

In those centers where the critical mass of patients is low, it is far from unacceptable to construct a shunt in a four-month-old infant with tetralogy, or to refer a child with patent arterial duct for surgical division through a left thoracotomy, or to advise a Senning procedure. Many children have died from dramatic confusion between convention and obsolescence, age and outdating, fashion and qualification. Now more than ever, we should not forget these distinctions.

\section{Effects of destabilization}

There remains another hazard for the river of pediatric cardiology as it moves towards the next millenniumfragmentation into refined subspecialties each dealing with a small part of the problem. This produces the danger of forgetting the whole patient. Are there not already seven different working groups within our Association of European Paediatric Cardiologists. We can be sure they will grow up. Let us hope that, in so growing, they will neither grow apart (as they will call for more and more space and time) nor be absorbed by other specialties such as radiology, obstetrics, or general cardiology.

What does up-to-date pediatric cardiology mean? It is a sum of many requirements. It needs a section of advanced neonatology, including all kinds of intensive care and monitoring. An obstetric department should be present on the same campus, with qualified staff interested in high-risk pregnancies, fetal medicine and interventional obstetrics. Highly sophisticated imaging facilities are required, including not only transthoracic echo/Doppler equipment, but also the newer devices to provide multidimensional or intravascular pictures, as well as transesophageal probes. Biplane digitized angiography, magnetic resonance imaging, and nuclear scanning are other obvious requirements which, in turn, require the services of engineers, anesthesiologists, radiologists, and physicists.

A specific catheter laboratory must be available, specially designed to accommodate very young and severely distressed patients with complex malformations who need various kinds of artificial support. It needs to be directed by someone very familiar with neonatal physiology and pharmacology, and fully trained in pediatric interventional cardiology. A high level section dealing with electrophysiology must be able to deal with routine electrocardiography, Holter monitoring and therapy, and must also take responsibility for any kind of invasive study or therapy, such as ablations or insertion of pacemakers. The pediatric cardiology unit needs to be combined with a sophisticated department specifically trained in and equipped for cardiovascular surgery in the young, even the newborn infant. A "multipurpose" pediatric campus is an essential for those who seek to develop a program for transplantation, including all clinical disciplines as well as the various sections of biology: immunology, pharmacology, bacterio-virology, pathology. A dedicated research team, dealing with basic sciences such as molecular biology and genetics, is very much a positive feature.

Such an entity has destabilizing effects on people as well as on services. Are there any of us who can claim his or her ability to meet all these functions? Certainly not! Which implies the need for multidisciplinary teams and, concomitantly, a redefinition of the role of the basic pediatric cardiologist. Should he or she be a general practitioner dealing only with screening of murmurs in childhood? Or should he or she be part of the team I have just mentioned? How many are needed? How should they be trained? All these questions are of paramount importance, and should be at the very heart of our concerns.

Explosion and fragmentation would also destabilize our departments. Many of these used to be more or less academic units of a conventional hospital with an outpatient clinic, one or two ultrasound machines and access to a central catheterization laboratory for two to three half-days a week. Such an organization will not be compatible with the requirements I have mentioned for the third millennium. There will, therefore, be a need to federate the various functions which are required, in a smaller number of special centers dealing with critical masses of patients, thus obtaining the necessary skill and expertise as well as the funds to face an increasing expenditure. In other words, we have to be prepared for further concentration, which must also mean the disappearance of some existing units.

Four years ago, at the World Congress of Cardiology in Manila, Jane Somerville made an English grammatical pun in stating: "The age of morphology and mythology is over. 'Whither pediatric cardiology?' is more likely to 
become 'Wither pediatric cardiology.' Enjoy it while it lasts. Most of pediatric cardiologists, certainly as structured now, could be out of a job by 2000 A.D." ${ }^{20}$ I disagree! Let us take up the new challenges. Let us say "goodbye" to our old dear long fleuve tranquille. Instead, let us redouble our efforts and be prepared to sail this new, complex, perverse, destructive, fascinating, cherished river whose name is still pediatric cardiology!

\author{
Service de Cardiologie Pédiatrique \\ Hopital Necker-Enfants Malades \\ 149 rue de Sèvres, 75743 Paris Cedex 15 \\ France \\ Tel. 331444943 41; Fax. 33144494340
}

\section{References}

1. Williams RC, Tucker CR. Echocardiographic diagnosis of congenital heart disease. Little/Brown, Boston, 1977.

2. Freed MD, Heymann MA, Lewis AB, Rochl SL, Kensey RC. Prostaglandin $\mathrm{E}_{1}$ in infants with ductus arteriosus dependent congenital heart disease. Circulation 1981; 64: 899-905.

3. Ludomirsky A, Huhta JC. Color Doppler of Congenital Heart Disease in the Child and the Adult. Futura Publishing Company Inc., Mount Kisco, New York, 1987.

4. Tynan M, Huggon I, Anjos R, Godman MJ, Rohmer J, Bethencourt A, Bjørnstad PG, Brode P, Deanfield J, Degiovanni J, Hess J, Kallfelz HC, Kramer H, Martin R, Maymone Martins FA, Mullholland HC, Piéchaud JF, Rey C, Sebenning W. Transcatheter occlusion of the persistent arterial duct. Report of the European Registry. Lancet 1992; 340: 1062-1066.

5. Laborde F, Noirhomme P, Karam J, Batisse A, Bourel P, SaintMaurice O. A new video-assisted thorascopic surgical technique for interruption of patent ductus arteriosus in infants and children. J Thorac Cardiovasc Surg 1993; 105: 278-280.

6. Waldman JD, Karp RB. How should we treat coarctation of the aorta? Circulation 1993; 87: 1043-1045.

7. Lock JE, Niemi T, Burke BA, Einzig S, Castañeda-Zuniga WR. Transcutaneous angioplasty of experimental aortic coarctation. Circulation 1982; 66: 1280-1286.

8. Rocchini AP, Beekman RH, Shacher GB, Benson L, Schwartz
D, Kan JS. Balloon aortic valvuloplasty: results of the Valvuloplasty of Congenital Anomalies Registry. Am J Cardiol 1990; 65: 784-789.

9. Burrows PE, Benson LN, Williams WG, Trusler GA, Coles J, Smallhorn JF, Freedom RM. Iliofemoral arterial complications of balloon angioplasty for systemic obstructions in infants and children. Circulation 1990; 82: 1697-1704.

10. Castañeda AR, Freed MD, Willams RG, Norwood JI. Repair of tetralogy of Fallot in infancy. J Thorac Cardiovasc Surg 1977; 74: 372-381

11. Piéchaud JF, Delogu AD, Iserin L, Aggoun Y, Cohen L, Sidi $\mathrm{D}$, KachanerJ. Traitement palliatif de la tétralogie de Fallot par dilatation infundibulo-pulmonaire percutaneé. Etude de $\mathbf{4 0}$ cas. Arch Mal Coeur 1994; 86: 573-579.

12. Castañeda AR, Norwood WI, Jonas RA, Colan SD, Sanders SP, Lang P. Transposition of the great arteries and intact ventricular septum: anatomical repair in the neonate. Ann Thorac Surg 1984; 38: 438-443.

13. Quaegebeur JM, Rohmer J, Ottenkamp J, Buis T, Kirklin JW, Blackstone EH, Brom AG. The arterial switch operation: an eight year experience. J Thorac Cardiovasc Surg 1986; 92: 361-384.

14. Sidi D, Planché C, Kachaner J, Bruniaux J, Villain E, Le Bidois J, Piéchaud JF. Anatomic correction of simple transposition of the great arteries in 50 neonates. Circulation 1987; 75: 429 . 435.

15. Transposition of the Great Arteries 25 years after Rashkind Balloon Septostomy. Vogel M, Buhlmeyer K (eds). Steinkopf Verlag, Darmstadt/Springer Verlag, New York, 1992.

16. Acar P, Sidi D, Kachaner J, Gournay V, Iserin L, Da Cruz E, Delogu A. Dérivations cavopulmonaires pour traiter les cardiopathies univentriculaires de l'enfant. Une expérience de 60 cas. Arch Mal Coeur 1993; 86: 601-607.

17. Fontan F, Baudet E. Surgical repair of tricuspid atresia. Thorax 1971; 26: 240-248.

18. Fontan F, Kirklin JW, Fernandez G, Costa F, Naftel DC, Tritto F, Blackstone EH. Outcome after a "perfect" Fontan operation. Circulation 1990; 81: 1520-1536.

19. Kachaner J, Le Bidois J, Vouhé P. Heart transplantation in children. In: Broyer M (ed). Transplantation. Balliére’s Clinical Paediatrics 1993; 1: 1017-1028.

20. Somerville J. Whither paediatric cardiology? Int J Cardiol 1991; 31: 273-280. 